3. Rudra R, Shelton E. Left lobe amoebic liver abscess. Postgraduate Medical Journal 1976; 52, 269-274.

4. Coia, LR, Myerson, RJ, Tepper, JE. Late effects of radiation therapy on the gastrointestinal tract. Int J Radiat Oncol Biol Phys 1995; 31:1213

5. Thompson JE, Jr, Forlenza S, Verma R. Amebic liver abscess: a therapeutic approach. Rev Infect Dis. 1985; 7:171-179

6. Chandran SR, Balakrishnan RK, Chinnasamy B, Srinivasan GK. Amebic Hepatopericardial fistula causing cardiac tamponade. Ann Trop Med Public Health 2012; 5:387-9.

\section{Fibrovascular Polyp of the Esophagus: A Case Series}

Fibrovascular polyp of the esophagus is a rare condition causing dysphagia, and only a few cases have been reported in the literature. Clinical symptoms vary from difficulty in swallowing to fatal asphyxiation or an incidental finding on upper gastrointestinal endoscopy. Usually, polyps are intraluminal and polypoidal lesions which arise from the cervical part of the esophagus.

\section{Case Series}

Two of the patient presented with insidious onset of progressive dysphagia over two years while the other two had recurrent respiratory infection and vomiting respectively. On Upper gastrointestinal endoscopy (UGIE), there was a pedunculated polypoidal structure in the lumen, with attachment to the wall just below the upper esophageal sphincter. A barium swallow was done in two of the patients which showed smooth lesions (Figure 1). One of them used to vomit the mass frequently and swallow it, however, the other patient who regurgitated a polypoidal mass through the mouth, after UGIE which was partially excised and reduced under anesthesia (Figure 2). Computed tomography of the neck and thorax revealed a polypoidal mass in the lumen of lower cervical esophagus (Figure 3).

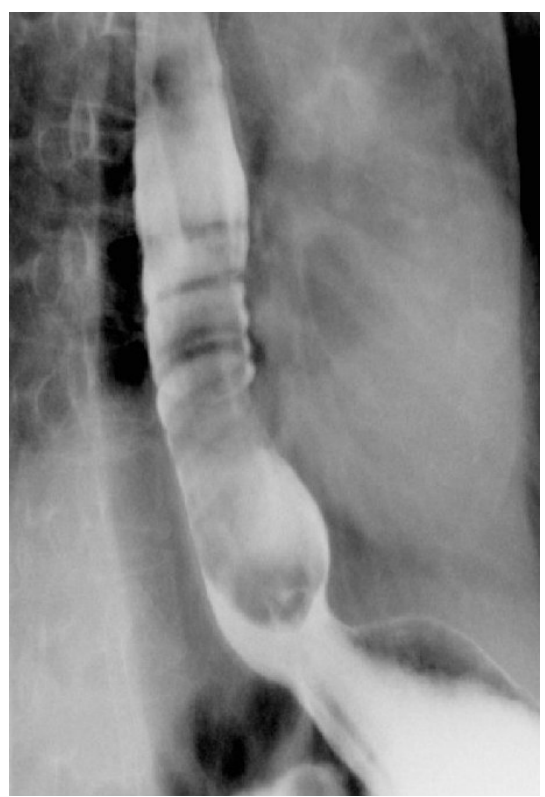

Figure 1: Dilated thoracic esophagus with smooth long filling defect which extends till the GE junction.

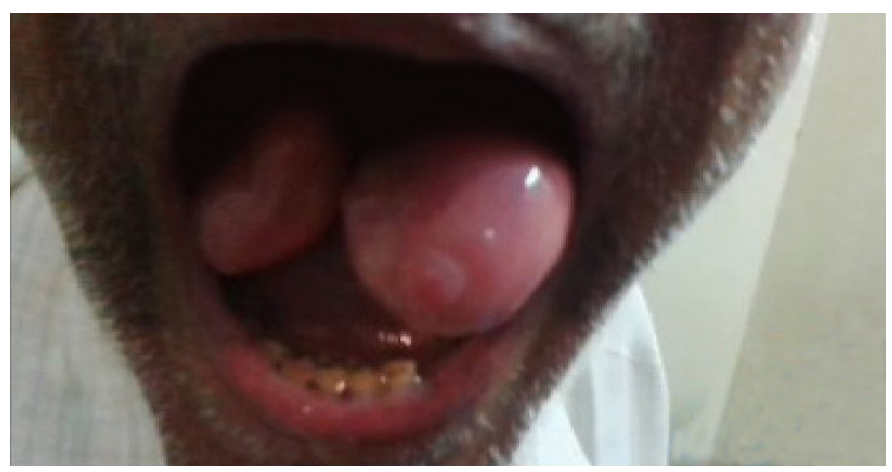

Figure 2: Regurgitation of the polyp.

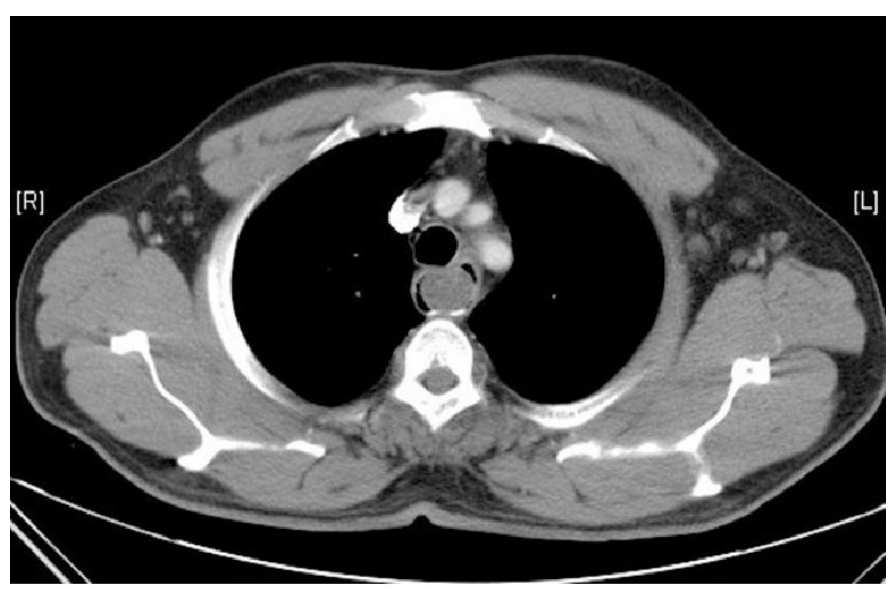

Figure 3: Large elongated polypoid soft tissue density lesion causing luminal narrowing. 
The esophagus was approached through a left cervical incision, and a soft, bulging mass was felt in the lumen of the entire cervical esophagus. Subsequently, a cervical esophagotomy was performed, which revealed a long pedunculated polypoidal structure in the lumen, with attachment to the wall of the esophagus, just below the cricopharynx. The entire polyp was delivered out of the lumen (Figure 4), and a complete sub mucous excision of the polyp was performed. The edges of the mucosal defect were approximated with absorbable sutures, and the esophagotomy was closed primarily. On pathological examination, polyps of varying size (Figure 5), lined by stratified squamous epithelium and had fibroblasts with immature collagen in a loose myxomatous stroma. There was also perivascular lymphoplasmacytic aggregate and inflammatory granulation tissue, suggestive of a benign fibrovascular polyp. The patient had an uneventful recovery and was discharged on the sixth postoperative day.

\section{Discussion}

Fibrovascular polyps are rare tumors of the esophagus (1 \% of benign tumors). These are slow growing, pedunculated tumors, most commonly arising from the cervical esophagus [Laimer-Haeckermann triangle]. This triangle is bound by the cricopharyngeus muscle above and the divergent longitudinal esophageal muscle fibers below. The unsupported submucosal tissue, due to the traction of esophageal peristalsis and swallowing, is elongated and enlarged to become giant intraluminal polyps which are larger than $5 \mathrm{~cm} .{ }^{1}$ These are commonly seen in elderly males, though they have been reported in younger adults and infants also., ${ }^{2,3}$

Histologically, they consist of various components [fibrous, vascular and lipomatous], accompanied by a network of vessels and have a covering of normal squamous epithelium. ${ }^{2}$ They had varied nomenclature depending upon, the major histological component, but are now classified by the World Health Organization as fibrovascular polyps. These can rarely undergo malignant transformation. ${ }^{4,5}$

Patients most commonly present with dysphagia [62-87\%], respiratory symptoms [25\%] or regurgitation

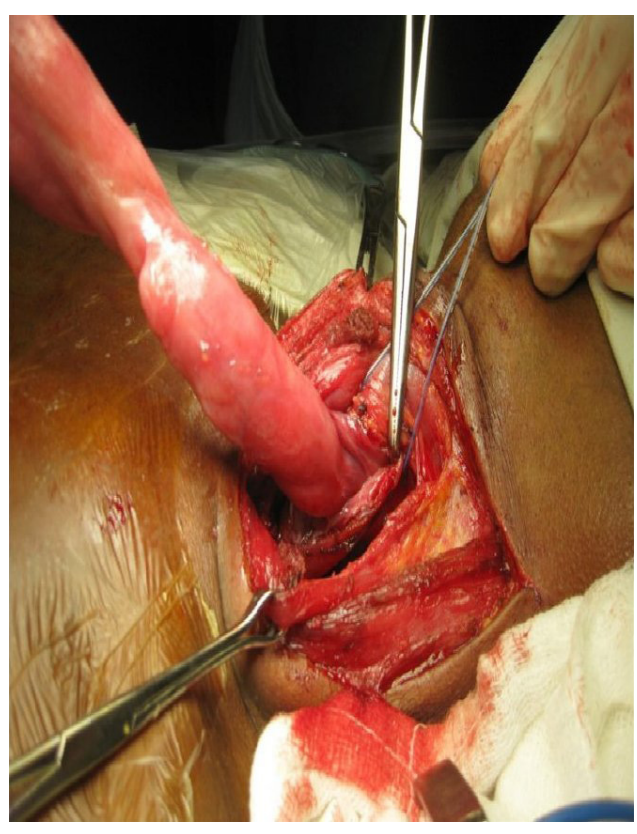

Figure 4: Intra-operative image of the fibro vascular polyp of the esophagus.

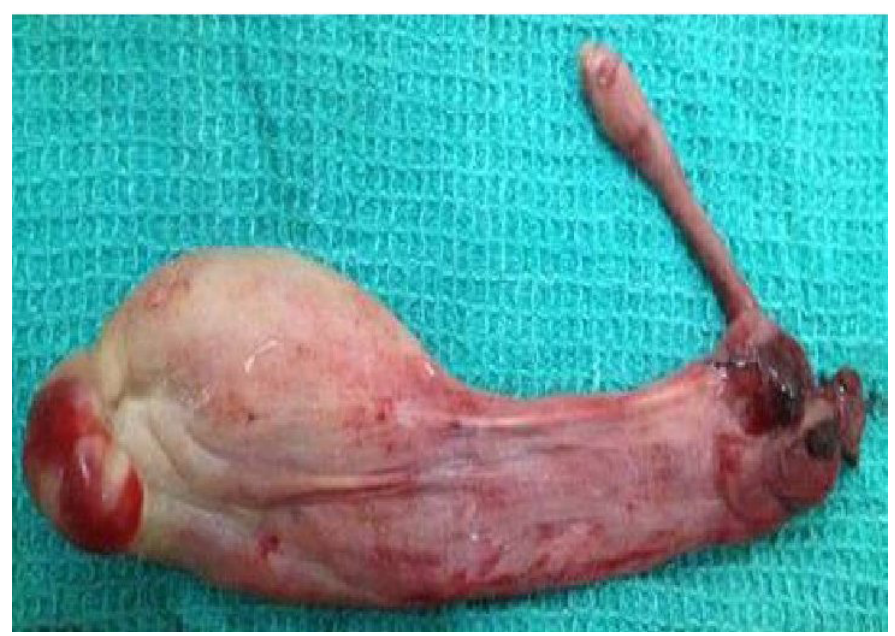

Figure 5: Surgically excised esophageal polyp.

[13-38\%]. Regurgitation of polyps can cause asphyxia, even leading to death. ${ }^{5}$ They may also be asymptomatic or have no specific symptoms. Unless there is obvious regurgitation, the diagnosis can be difficult. Both endoscopy and imaging are used for diagnosis. Because the polyp is covered by normal looking mucosa and is soft in consistency, these lesions are easily missed, on UGIE, in up to $25 \%$ of patients. ${ }^{7}$ On barium study, they appear as filling defects with a widened esophagus, though occasionally it can appear normal, as in our case. ${ }^{1} \mathrm{CT}$ 
scan is diagnostic and helps in planning for surgery. ${ }^{8} \mathrm{CT}$ scan shows a heterogeneous lesion with soft tissue density and fat density intermingled. A thin rim of contrast is usually seen around the polyp, confirming its intraluminal position. ${ }^{2}$ Endoscopic ultrasonography is most useful to assess the origin of the base and vascularity if planning for endoscopic excision of giant polyps. ${ }^{5}$

Surgical excision is recommended even for asymptomatic patients, to obviate the small risk of laryngeal obstruction, bleeding or malignant transformation. ${ }^{1,2}$ The described surgical approaches are endoscopic excision, laser ablation, and surgical excision by cervical or transthoracicesophagotomy. A combined transabdominal and cervical approach is also described. ${ }^{3}$ Esophagectomy is done only when a tumor is suspected to be malignant or when it is difficult to remove the tumor through esophagotomy. ${ }^{7}$ Endoscopic excision is usually done for small polyps, though a large polyp has been excised successfully. ${ }^{9}$

Cervical esophagotomy is the most common approach for surgical excision where esophagus was approached through a left cervical incision. Complete sub mucous excision of the polyp was performed, and the edges of the mucosal defect were approximated with absorbable sutures, and the esophagotomy was closed primarily. The cervical location of the tumor, easy accessibility, and minimal morbidity makes this approach attractive. Prior imaging and localization of the tumor base is essential to decide the side to approach, and site of the incision. ${ }^{8}$

Histologically, the tumor arises from the submucosa hence submucosal excision reduces the potential of recurrence, compared to transecting the stalk at its base. ${ }^{6}$ Though rare, there have been a few case reports of recurrent fibrovascular polyps. ${ }^{5}$ Almost always it is due to incomplete excision or due to residual tissue around the polyp base. ${ }^{1,6}$

To conclude, fibrovascular polyps are rare, benign tumors of the esophagus. Submucosal excision is the treatment of choice. Awareness of these tumors and a high degree of suspicion is required to diagnose and treat these potentially fatal tumors.

\section{MYLA YACOB \\ BEULAH ROOPAVATHANA \\ SAM V GEORGE \\ VIJAY ABRAHAM \\ INIAN SAMARASAM}

Christian Medical College and Hospital, Vellore, Tami Nadu, India - 632004

Corresponding Author: Dr Myla Yacob Email:yacobmyla@yahoo.com

\section{References}

1. Lee SY, Chan WH, Sivanandan R, Lim DTH, Wong WK. Recurrent giant fibrovascular polyp of the esophagus. World J. Gastroenterol. 2009;15:3697-3700.

2. Levine MS, Buck JL, Pantongrag-Brown L, Buetow PC, Hallman JR, Sobin LH. Fibrovascular polyps of the esophagus: clinical, radiographic, and pathologic findings in 16 patients. AJR Am J Roentgenol. 1996;166:781-787.

3. I H, Kim JS, Shim YM. Giant fibrovascular polyp of the hypopharynx: surgical treatment with the biappoach. J. Korean Med. Sci. 2006;21:749-751.

4. Jakowski JD, Wakely PE. Rhabdomyomatous welldifferentiated liposarcoma arising in giant fibrovascular polyp of the esophagus. Ann Diagn Pathol. 2009;13:263268.

5. Drenth J, Wobbes T, Bonenkamp JJ, Nagengast FM. Recurrent esophageal fibrovascular polyps: case history and review of the literature. Dig. Dis. Sci. 2002;47:25982604.

6. Peltz M, Estrera AS. Resection of a giant esophageal fibrovascular polyp. Ann. Thorac. Surg. 2010;90:10171019.

7. Kanaan S, DeMeester TR. Fibrovascular polyp of the esophagus requiring esophagectomy. Dis. Esophagus. 2007;20:453-454.

8. Yannopoulos P, Manes K. Giant fibrovascular polyp of the esophagus - imaging techniques can localize, preoperatively, the origin of the stalk and designate the way of surgical approach: a case report. Cases J. 2009;2:6854.

9. Zhang J, Hao J, Li SWH, Zhang S. Successful endoscopic removal of a giant upper esophageal inflammatory fibrous polyp. World J. Gastroenterol. 2009;15:5236-5238. 